\title{
Correction to: Life cycle assessment of electricity generation: a review of the characteristics of existing literature
}

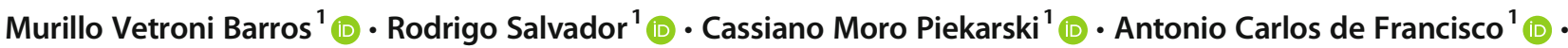 \\ Fausto Miguel Cereja Seixas Freire ${ }^{2,3}$ (D)
}

Published online: 30 July 2019

(C) Springer-Verlag GmbH Germany, part of Springer Nature 2019

\section{Correction to: The International Journal of Life Cycle} Assessment https://doi.org/10.1007/s11367-019-01652-4

The original version of this article unfortunately contained a mistake which was missed during typesetting. The figures of Graph 1 and Figure 6 were switched.

The correct versions are given below.

The original article has been corrected.

Publisher's note Springer Nature remains neutral with regard to jurisdictional claims in published maps and institutional affiliations.

The online version of the original article can be found at https://doi.org/ $10.1007 / \mathrm{s} 11367-019-01652-4$

Murillo Vetroni Barros

murillo.vetroni@gmail.com

1 Sustainable Production Systems Laboratory (LESP), Federal University of Technology - Parana (UTFPR), Ponta Grossa, Brazil

2 Center for Industrial Ecology (CIE), University of Coimbra, Coimbra, Portugal

3 ADAILAETA, Department of Mechanical Engineering, University of Coimbra, Coimbra, Portugal 


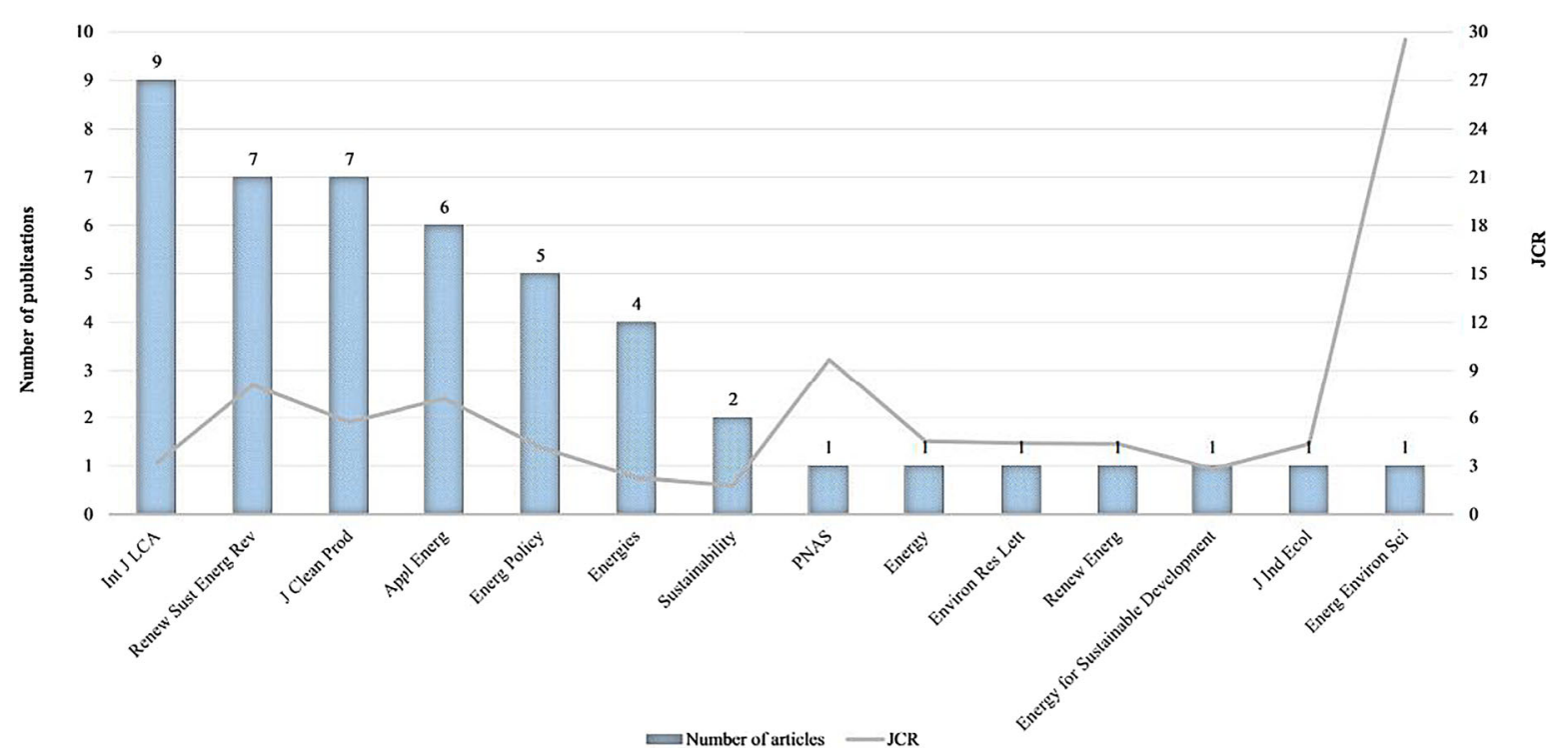

Graph 1 Distribution of articles published in journals and journal's JCR

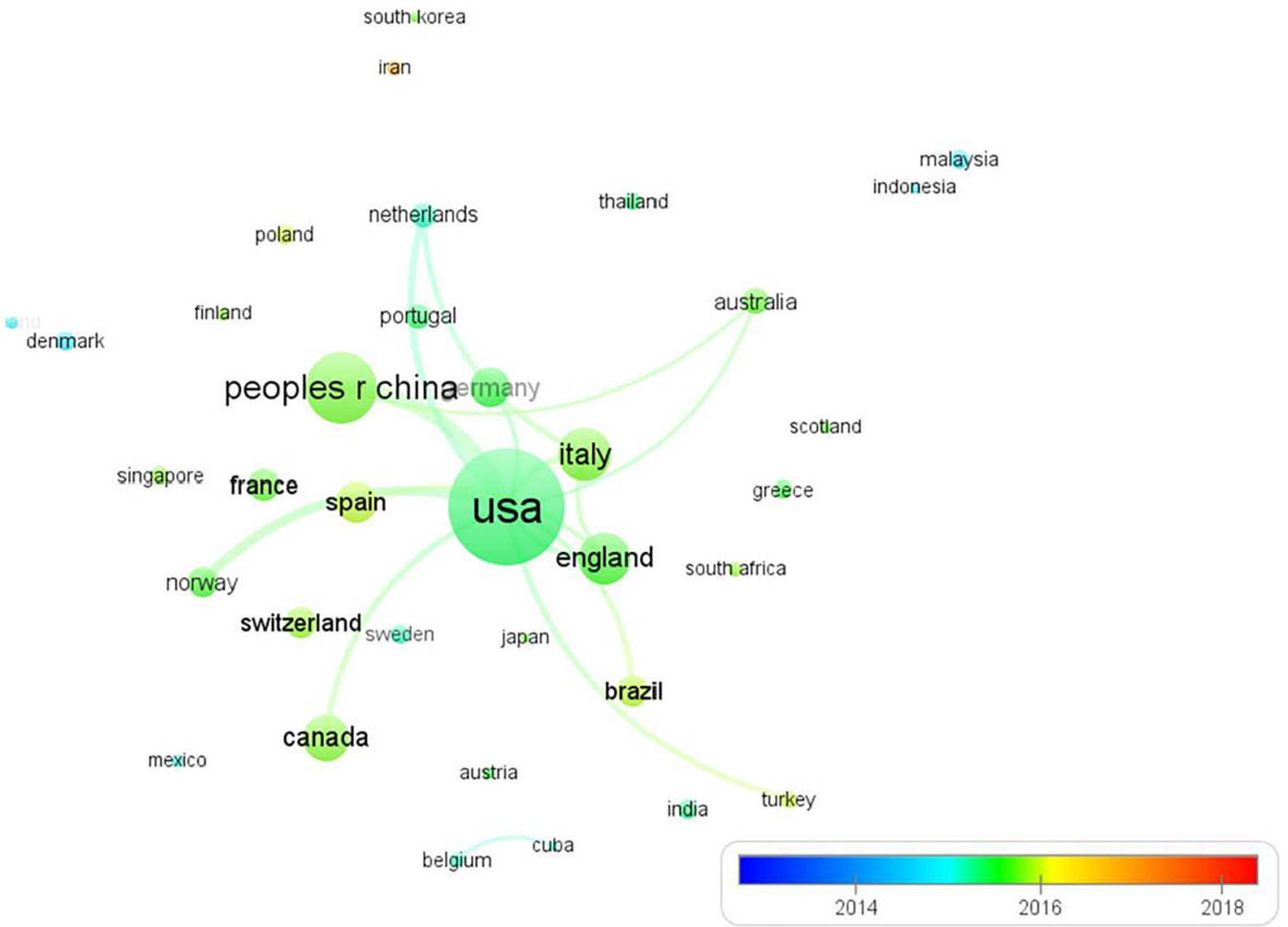

Fig. 6 Country co-occurrence - world research - main countries who have published papers on the theme 